\title{
POLÊMICAS NAS REVERBERAÇÕES CRÍTICAS DE BACURAU
}

\author{
Polemics in Bacurau's critical reverberations \\ Controversias en las reverberaciones críticas de Bacurau
}

Ercio Sena

Professor do Programa de Pós-Graduação em Comunicação Social da PUC Minas

erciosena@gmail.com

Juliana Gusman

Doutoranda do Programa de Pós-Graduação em Meios e Processos Audiovisuais ECA-USP

julianamrgusman@gmail.com

\section{Resumo}

Pretendemos problematizar a polêmica em torno do filme Bacurau (2019), de Kleber Mendonça Filho e Juliano Dornelles. Objetiva-se mapear intervenções dissonantes presentes na circulação de discursos sobre a obra, especificamente na crítica jornalística. Tenciona-se identificar e analisar as principais chaves de leitura acionadas por essas falas especializadas, localizando a confrontação política que permeia diferentes interpretações.

Palavras-chave: Bacurau. Polêmica. Crítica jornalística.

\begin{abstract}
We intend to problematize the controversy around the movie Bacurau (2019), directed by Kleber Mendonça Filho and Juliano Dornelles. The purpose of this article is to place a set of dissonant interventions that rise in the circulation of discourses about the film, specifically in journalistic criticism. We aim to identify and analyze the main reading keys triggered by these specialized speeches, locating the political confrontation that permeates different interpretations.
\end{abstract}

Key words: Bacurau. Polemics. Journalistic criticism.

\section{Resumen}

Pretendemos problematizar la controversia en torno a la película Bacurau (2019), de Kleber Mendonça Filho y Juliano Dornelles. El objetivo es mapear un conjunto de intervenciones disonantes presentes en la circulación de discursos sobre la película, específicamente en la crítica periodística. Se pretende identificar y analizar las principales claves de lectura activadas por estos discursos especializados, ubicando la confrontación política que impregna diferentes interpretaciones.

Palabras clave: Bacurau. Controvérsia. Crítica periodística. 


\section{BACURAU, CRÍTICA E POLÊMICA}

Este artigo pretende reflexionar sobre a polêmica estabelecida em torno do filme Bacurau (Kleber Mendonça Filho; Juliano Dornelles, 2019). A obra se passa no Oeste pernambucano, em um pequeno povoado homônimo que acaba de perder sua matriarca, dona Carmelita (Lia de Itamaracá). Aos poucos, coisas estranhas começam a atemorizar este pedaço do sertão: objetos não identificados circulam pelo céu e estrangeiros quebram a pacata rotina da cidade. Após algumas mortes repentinas, Teresa (Bárbara Colen), Domingas (Sônia Braga), Pacote (Thomas Aquino), Plínio (Wilson Rabelo), Damiano (Carlos Francisco), Lunga (Silvero Pereira) e outros habitantes percebem que estão sendo atacados. Diante da ameaça, precisam resistir. Neste trabalho, não faremos uma avaliação direta sobre o longametragem, mas sobre sua repercussão, polarizada, na crítica jornalística especializada.

Entendemos, com Rosana Soares e Gislene Silva (2016), que para compreender uma obra não basta discutir seus elementos internos, vinculados a estratégias narrativas e opções estéticas; é importante considerar suas demandas externas, que se originam nos contextos de produção e, neste caso, de circulação do filme. Objetivamos, então, evidenciar diferentes interpretações e ressignificações sobre os sentidos nele presentes, problematizando as principais chaves de leitura acionadas por estas reverberações. Se a crítica especializada contribui para a reflexão e consolidação das obras avaliadas; orienta a percepção do público sobre elas; propõe novos modos de realização; e estabelece critérios de análise (PAGANOTTI; SOARES, 2019), podemos considerá-la um espaço privilegiado de circulação, capaz de nortear leituras legitimadas sobre o objeto tensionado. Assim como as representações do cinema, esforços criativos que lastreiam visões de mundo (HALL, 2016), este tipo de produção jornalística também está inserido em aspectos mais amplos de disputas de poder. Os discursos propostos por estas diferentes manifestações simbólicas participam da luta pela imposição de estatutos de verdade capazes de definir, conforme Michel Foucault (2019), o que será estimado, valorizado e considerado relevante em enunciados coletivos. Ao efetuarmos uma "crítica das críticas" (PAGANOTTI; SOARES, 2019), almejamos, portanto, desconstruir as falas cristalizadas nestas dinâmicas.

Costuraremos esta desconstrução a partir da positividade da palavra polêmica. Segundo Ruth Amossy (2017), o termo é usualmente recuperado para apontar a emergência de percepções depreciativas em torno de certos eventos ou expressões culturais. Ao tomarmos Bacurau como obra polêmica, poder-se-ia aferir que existem, unicamente, apreciações negativas sobre o filme. Isso ocorre porque, em geral, esta adjetivação carrega má 
reputação. Amossy, porém, busca um novo estatuto para o conceito. Reconhece, nele, o mérito de mobilizar argumentos e paixões em torno dos significados que determinada obra propõe. A polêmica é combustível que pode alimentar a ressonância e consumo, estimulando difusões em ampla escala. Numa sociedade empenhada em produzir espetáculos, ela é mais uma atividade lúdica a orientar protagonismos em confrontos argumentativos. Amossy entende que a polêmica na mídia notabiliza práticas envolvidas nas batalhas discursivas descritas por Foucault -, ainda que nem sempre apoiadas em profunda reflexão.

É a polêmica, portanto, que projeta as circulações, antagônicas, de Bacurau. Isto posto, ela não nasce de uma corriqueira ou simples controvérsia; ao contrário, ela retoma as lutas mais persistentes na vida social brasileira. As críticas jornalísticas sobre Bacurau destacam, precisamente, o seu poder de ecoar importantes conflitos e assimetrias que marcam o nosso tempo. Por meio delas, exaltou-se a vingança e se denunciou o conluio de poucos e diferenciados brasileiros com a exploração da maioria - sem deixar de considerar, obviamente, aspectos como escolhas de roteiro, enquadramentos de personagens e o manejo dos gêneros cinematográficos na trama. Com destaque para o uso da violência, observou-se tanto a celebração da resistência como a incapacidade de a esquerda brasileira, espelhada da narrativa, expressar um pensamento inteligente, tomando como deletérias e ultrapassadas suas crenças revolucionárias. Bacurau condensou e retomou esses e outros sentidos em sua comunicabilidade, inspirando confrontações em torno de questões urgentes.

Para problematizarmos a polêmica que tangenciou a crítica cultural sobre o filme, selecionamos, em um universo de 67 artigos divulgados em diferentes veículos de jornalismo, entre agosto e outubro de 2019, as falas que julgamos mais representativas destas batalhas discursivas evidenciadas. Destacamos a opinião de 16 articulistas que assumiram posições polarizadas em relação a obra ${ }^{1}$. Entre as críticas positivas, reunimos os textos de José Geraldo Couto, do Instituto Moreira Salles; Inácio Araújo, da Folha de S. Paulo; Ivana Bentes, da Revista Cult; Arnaldo Bloch, de O Globo; Luiz Zanin, do Estadão; e Rodrigo Nunes, do El País. Entre as críticas negativas, abordamos os trabalhos de Miguel Forlin, do Estadão; Marcelo Coelho, Demétrio Magnoli, Samuel Pessôa e Rodrigo Teixeira, todos da Folha de S. Paulo; Eduardo Escorel, da revista Piauí; Isabela Boscov, da revista Veja; Durval Muniz, do blog Saiba Mais; Andrea Ormond, da revista Cinética; e Rodrigo Perez Oliveira, dos Jornalistas Livres. Identificamos quatro eixos estruturantes de argumentação que permeiam estes textos: ponderações acerca dos gêneros cinematográficos operados pelos diretores;

\footnotetext{
${ }^{1}$ Obviamente, não desconsideramos possíveis nuances presentes nos textos assim categorizados.
} 
articulações entre o filme e o contexto sócio-político no qual ele está inserido; o debate ético sobre a violência presente na narrativa; e a crítica das próprias reverberações midiáticas de Bacurau.

\section{HOLLYOOD É AQUI? GÊNEROS CINEMATOGRÁFICOS E A CULTURA ESTADUNIDENSE}

A crítica jornalística dividiu-se, certamente, em função do conteúdo político de Bacurau, como veremos adiante. Entretanto, tensionamentos sobre as estratégias formais e estéticas do longa também suscitaram polemizações politizadas. De uma forma geral, os artigos direcionaram discussões para o diálogo estabelecido entre o filme e o cinema hollywoodiano; contemplam, especialmente, os usos dos gêneros cinematográficos forjados por essa tradição e suas implicações. Os articulistas concordam, em grande medida, que Bacurau absorve influências de formatos narrativos bastante estratificados em suas convenções, de fácil apreensão e grande popularidade (XAVIER, 2005) - marcadamente o western, a ficção científica e o suspense. No entanto, a conversação com essa linguagem comercial é apreendida, pelos críticos, de maneiras divergentes.

Os textos favoráveis ressaltam positivamente a normatividade de Bacurau. Para José Geraldo Couto, em texto divulgado pelo site do Instituto Moreira Salles, a obra consegue articular símbolos universais, vinculados às formas representativas do cinema estadunidense, com símbolos locais. Esta estratégia narrativa, para ele, evidencia o que há de comum entre diferentes experiências sociais, culturais e estéticas. Por exemplo, “os amplos planos gerais de planície e vegetação rala evocam, sim, o western, mas também os enquadramentos abertos dos filmes de sertão do cinema novo. Um crepúsculo sangrento do velho oeste é seguido pelo típico luar do sertão" (COUTO, 2018). Trata-se, portanto, de uma relação profícua, que garante a circulação e a recepção da obra entre diferentes públicos, atraídos por uma narrativa embebida de referências com as quais são capazes de se identificar.

Inácio Araújo, colunista da Folha de S. Paulo, afirma que a recuperação de convenções propostas pelo cinema norte-americano operada por Bacurau é feita de maneira antropofágica, em concordância com a argumentação desenvolvida pela professora e pesquisadora Ivana Bentes, na Revista Cult. Para ela, os gêneros são deglutidos em uma expressividade caracteristicamente brasileira, que não deixa de recuperar suas próprias tradições. A estética da fome de Glauber Rocha se entranha nesse "faroeste transgênero", abalizado por "clichês reinventados". Conforme estes articulistas, Bacurau se apropria de 
formatos cinematográficos consolidados, familiares e próximos do público, para digeri-los em novos termos, em sintonia com práticas do cinema terceiro-mundistas que buscaram transcender a dicotomia entre um cinema autenticamente nacional e a alienação hollywoodiana (SHOHAT; STAM, 2006). Temos a defesa de um cinema orgulhoso de sua bastardia e consciente das ressignificações políticas que propõe.

As críticas negativas, no entanto, qualificaram esta imbricação de linguagens como preguiçosa, sustentando que o diálogo do filme com os gêneros oriundos da produção estadunidense resulta, somente, em uma cópia malfeita desses formatos. Kleber Mendonça Filho e Juliano Dornelles manipulariam e instrumentalizariam "elementos cinematográficos, retirando-os dos seus locais de origem - portanto, descontextualizando-os -, mas recolocando-os em um cenário no qual eles nunca adquirem um significado próprio ou próximo da sua dimensão original” (FORLIN, 2019), diz Miguel Forlin, em artigo publicado do Estadão. O articulista defende certa pureza dos gêneros utilizados, que perderiam sua integridade e relevância se deslocados de seus usos mais comuns. $\mathrm{O}$ arranjo proposto por Bacurau, além de macular linguagens consagradas, configura, para o autor, uma contradição. Para Forlin, "Bacurau supõe cutucar a presença violenta e impositiva do norte-americano [...], o que se choca com a opção de trabalhar um gênero essencialmente americano" (FORLIN, 2019). O autor parece desconsiderar quaisquer possibilidades de ressignificação desses formatos, tomados apenas em sua originalidade. Supõe a discrepância entre a forma que, supostamente, elogia a cultura estadunidense e o conteúdo do filme que a rechaça.

Outro ponto comum entre as críticas negativas é a comparação da produção de Kleber Mendonça Filho e Juliano Dornelles com a filmografia de Quentin Tarantino, e não em uma chave elogiosa. Demétrio Magnoli, da Folha de S. Paulo, defende que estes realizadores lançam mão de uma "estética fascista que investe na sedução do sangue", contribuindo, supostamente, com a alienação e a animalização do público: "Os diretores, em transe populista, conclamam os espectadores a aplaudir freneticamente, pavlovianamente, as gráficas execuções dos invasores americanos. Hollywood é aqui” (MAGNOLI, 2019). Para Magnoli, a aproximação de Bacurau com elementos do cinema hollywoodiano também garante um engajamento do público, mas não por causa de sua familiaridade com as formas comerciais. A estética fascista é tida como a principal, e talvez única, fonte de persuasão das audiências, manipuladas pela retórica da violência injustificada.

Para além deste entrave, é interessante notar que apesar de a crítica especializada se debruçar, insistentemente, sobre os aspectos ficcionais da obra, percebemos que os artigos 
analisados, em sua multiplicidade de abordagens, insistem em uma leitura quase documental de Bacurau. Na Folha de S. Paulo, Marcelo Coelho chega a dizer, por exemplo, que o trabalho de Mendonça Filho e Dornelles pode operar como uma possível previsão do futuro. Supõe que "alguma agência de turismo no Texas talvez esteja mesmo planejando oferecer a seus clientes a diversão proposta no filme" (COELHO, 2019). Para Bentes, Bacurau é uma radiografia do presente: "sintetiza o Brasil brutal, distópico". O filme seria uma "espécie de documentário sobre o imaginário em que estamos" (BENTES, 2019). Já Samuel Pessôa, na Folha, criticou, até mesmo, a falta de precisão factual da película que, para ele, propõe um retrato simplificado do Brasil contemporâneo. Reclama, por exemplo, da falta de uma discussão aprofundada sobre o papel das igrejas evangélicas na configuração política atual, o que não poderia estar ausente, a seu ver, em uma narrativa comprometida com a representação realista das classes populares.

Mesmo que o realismo de Bacurau seja atravessado pelo mágico e pelo fantástico como na aparição de Carmelita, a matriarca falecida da comunidade, que assombra o inimigo do povo - cobra-se que o filme apresente uma fidelidade ao mundo histórico que, em verdade, ele não promete. Nas diferentes leituras sobre a obra, o universo diegético de Bacurau perde, por vezes, sua autonomia ficcional; o longa se torna um documento do passado, do presente e do futuro, uma apropriação incisiva, principalmente, quando os críticos pensam sobre suas relações com contexto no qual está inserido.

\section{DO TEXTO AO CONTEXTO}

As produções culturais não apenas buscam refletir uma ordem social, mas são elementos que a constituem (WILLIAMS, 1992). Com Stuart Hall (2016), lembramos que as representações propostas por elas, especialmente no cinema, administram sociabilidades e perspectivas de mundo. Por isso, supomos, há uma forte repercussão de uma ficção que se entrelaça, explicitamente, com o enredo da vida política nacional. A nação representada pelo lugarejo de Pernambuco não foge à regra de um mundo permeado pelo ódio à democracia, cada vez mais difícil de ser mantida, mesmo em sua forma aparente. Não obstante, tanto no filme como no mundo histórico as reiteradas negações de direitos e a emergência de formas autoritárias estimulam caminhos alternativos frente às imposições de um neoliberalismo total - no caso brasileiro, representado pelo governo de Jair Bolsonaro; na obra, encarnado pelos ianques assassinos. Logo, repõe-se no debate crítico sobre Bacurau o papel do Estado, as dinâmicas dos conflitos sociais e as narrativas conformadoras da cultura nacional, 
assinalando-se, em alguns textos, novas tradições na ruptura de pensamentos dominantes. Para Ivana Bentes:

Há algo de profundamente perturbador em Bacurau, de Kleber Mendonça Filho e Juliano Dornelles, talvez o mais importante filme contemporâneo sobre o Brasil distópico da era Bolsonaro. Mesmo tendo sido filmado antes das eleições de 2018 e da catástrofe política em andamento, Bacurau é um filme visionário e violento, uma ficção científica e política que não tem nada de alegórica. Ao contrário, é explícita e brutal, de uma lucidez aterradora. (BENTES, 2019).

Acredita-se que Bacurau apresenta o diagnóstico e o antídoto da distopia brasileira do momento atual, marcado pelo bolsonarismo. Somente um povo coeso, orientado para resistir às ofensivas dos invasores - os "americanos" - poderia sobreviver a uma democracia de baixa intensidade, marca da realidade política brasileira que, esta sim, apresenta um roteiro inimaginável na ordem pública. Bentes entende que "diante de um neoliberalismo que fracassou na sua utopia de mercado, diante de uma democracia em agonia, os sujeitos, os cidadãos, a comunidade também querem partilhar e participar da violência como forma de resistência e sobrevivência”. (BENTES, 2019).

Destaca-se que o filme contesta o atual governo, também, através de um enfrentamento à sua agenda moral. O principal herói de Bacurau, Lunga, é uma personagem nem homem, nem mulher - que pertencente a um grupo execrado no discurso e na ação bolsonarista. $\mathrm{Na}$ obra, outros sujeitos fora da norma também têm reconhecimento e acolhimento da comunidade - como Darlene (Danny Barbosa), uma mulher trans e negra que vigia a entrada da cidade. "Os personagens de Bacurau trazem nos corpos, nos cabelos, na cor da pele, um Brasil que emergiu e ganhou visibilidade. Homens e mulheres, negros e negras, trans, putas, os caboclos e povos originários" (BENTES, 2019). O combate à naturalização da indiferença e do desprezo com o povo de Bacurau, metonímia das classes espoliadas no país, é uma reação à conformidade com as anomalias produzidas nas sociedades que os desumanizam. Energias resistentes são liberadas por meio da arte, diante do inóspito cotidiano dos deserdados do Brasil. Na película, apontam os críticos, busca-se reivindicar e valorizar a cultura desses grupos esquecidos, populares. Se a cultura já foi considerada um apanágio dos homens cultos ou privilégio de uma minoria civilizada (BURKE, 2008), Bacurau reitera, contra essa visada, o protagonismo de um povo que reivindica suas próprias tradições como culturais. Para parte da crítica especializada, nele se afirma a construção narrativa da memória 
histórica da comunidade, orgulhosa, por exemplo, de seu museu, fazendo da reminiscência a baliza de um presente, ao fim e ao cabo, triunfante. Para Bentes, o filme, antes de tudo, aborda e engrandece

...um Brasil das cidadezinhas do interior completamente conectadas com o urbano. Atravessadas por redes de celular, tecnologias de vigilância e controle, telas de LED, drones, carros e motos possantes, distribuição de psicotrópicos e remédios que controlam o humor, uma cidade rústica, mas que poderia protagonizar um episódio de Black Mirror e que querem apagar do Google Mapa. (BENTES, 2019).

Por isso, a fração da crítica que aclama a produção a recebe, também, como obra catártica, cuja linguagem impactante retoma os discursos da valorização dos colonizados que, segundo Bentes, "inventam uma mística política vinda do povo" (BENTES, 2019). Já que as mobilizações e resistências não se apresentam de forma significativa nas ruas e na vida pública, na ficção o comum se realiza como uma purgação à violação e ao desespero de uma ausência de ação política. Assim, Bacurau projeta possibilidades de ação disruptiva de certas comunidades, “[...] os indígenas, a juventude periférica, as esquerdas, os estudantes universitários, os negros e negras" que, até o momento, "desconsideraram o discurso radical, de pegar em armas, usar a força física, se armar para fazer a disputa política" (BENTES, 2019). No filme, eles se erguem não apenas contra a investida imperialista simbolizada pelos estadunidenses, mas contra figuras menores da política brasileira, representadas na personagem do prefeito local, Tonny Jr. (Thardelly Lima), e contra o preconceito da classe média sulista, incorporada pelos "forasteiros" (Karine Telles e Antonio Saboia) alinhados ao projeto de extermínio dos americanos. Os emergentes e persistentes grupos de LGBTs, pobres e marginais são representados em Bacurau como sujeitos combativos, pinçados na memória que exala uma narrativa com intento libertário.

Em alguns textos analisados, observa-se, então, que a obra recupera uma imagem neocolonizadora para afirmar as relações sociais do Brasil em uma alegoria cuja intenção é produzir uma representação cultural diversa. $\mathrm{O}$ filme se propõe dispor o real ancorando-se em uma representação que desafia reproduções comuns sobre o povo e a brasilidade. Por essa perspectiva, Bacurau torna-se um manifesto para a parcela que se viu ameaçada pelo triunfo da ultradireita na última eleição presidencial. Aclamado como protesto político, a projeção emblemática da realidade nacional é assimilada em tons de aprovação. Bacurau sintetizou uma representação tomada quase como documento histórico, empenhando em denunciar as mazelas que atravessam e se perpetuam na história do Brasil. 
No entanto, os articulistas do outro polo argumentativo da batalha discursiva, apesar de reconhecerem a eficácia desse gesto, apontam artimanhas manipulatórias. Marcelo Coelho, colunista da Folha, não tem dúvidas de que Bacurau é uma obra de resistência "diante do pesadelo de violência e bizarrice que estamos vivendo no Brasil. Mas o sucesso de Kleber Mendonça Filho me parece mais um sintoma de desespero emocional do que de inteligência política" (COELHO, 2019). Para Coelho, Bacurau reencena "o mito do brasileiro puro e inocente". Na comunidade, não há divisões internas. "Se há algum brasileiro calhorda, é político ou é do sul" (COLEHO, 2019). Questiona-se, portanto, o retrato rascunhado do povo que, conforme o crítico, é recebido pelo público sem nuances e contradições. Segundo parte da crítica especializada, não seria possível elogiar a resistência de uma comunidade que “precisa derramar sangue para encontrar sua plenitude” (TEIXEIRA, 2019).

\begin{abstract}
À matança dos americanos, responde-se com matança e meia. Eis o Brasil vingado, e parte da plateia aplaudindo o derramamento de sangue organizado pelo assassino local. [...] Horrorizar-se diante do massacre de Canudos é uma coisa. Outra coisa, que nada tem de progressista, é confiar que uma reedição de Canudos possa ter sucesso. (COELHO, 2019).
\end{abstract}

Como podemos notar, para as falas negativizadas de Bacurau a obra perde sua verossimilhança e capacidade de reflexão política quando opõe, de forma maniqueísta, a violência dos nordestinos, tida como legítima, e a agressividade dos forasteiros, encarnações de todo mal na obra cinematográfica. As figurações da violência tornam-se, logo, outro ponto polêmico central.

\title{
4 QUEM TEM QUE MORRER? VIOLÊNCIA E RESISTÊNCIA
}

Nas relações estabelecidas entre Bacurau e o contexto sócio-histórico ao qual ele se refere, destaca-se, especialmente, a polêmica sobre as representações da violência na narrativa; especialmente uma violência mais evidente, gore, denominada por Slavoj Zizek (2014) como "subjetiva", diretamente visível e exercida por um agente claramente identificado. Em Bacurau, a violência que polarizou opiniões e leituras é, em grande medida, gráfica. Tanto nas recepções favoráveis como nas desfavoráveis, o foco, no entanto, foram os atos cometidos pelo povo de Bacurau, frente à ameaça dos caçadores estrangeiros cujo objetivo era aniquilar os habitantes daquele canto remoto do sertão.

Por um lado, a crítica especializada encarou a violência de Bacurau, mais especificamente, a violência praticada pelos "bacurauenses", como uma necessidade, como 
estratégia de luta para garantir a sobrevivência do povoado. Luiz Zanin, do Estadão, argumenta:

Queriam o quê? Que pedissem gentilmente aos assassinos para que voltassem às suas casas e revisassem seus conceitos, como se diz hoje? $\mathrm{Ou}$ que se deixassem abater sem opor a menor resistência? Dadas as condições expostas na ficção, a quem iriam recorrer? À polícia, ao juiz de paz, ao pároco? Os habitantes de Bacurau, cidade que sumira do mapa, só tinham a si mesmos se quisessem sobreviver. [...] Em terra sem lei, apenas a violência do ocupado se contrapõe à violência do ocupante. (ZANIN, 2019).

A violência é encarada como resistência, como catarse ou como uma justa vingança nas palavras de Arnaldo Bloch, n’O Globo, “uma vingança que não é movida pela pura crueldade, ainda que tenha lá seus requintes, pois ninguém é de ferro depois de levar bala de traíra" (BLOCH, 2019). Dados históricos são acionados para legitimar esse argumento. Inácio Araújo afirma que "sob ameaça de morte não é raro populações se unirem de maneira unânime. Normalmente ocorre com países em guerra, por exemplo" (ARAÚJO, 2019). Como postulava Franz Fanon (1961), "a violência do colonizado, temos dito, unifica o povo" (FANON, 1961, p. 91) A comunidade, diante de inimigos fantasiosos ou reais, se apropria da violência como "ferramenta de empoderamento e de resistência. Uma saída possível do lugar de vítima para a de vingadores" (BENTES, 2019).

Ao contrapor a violência dos invasores com aquela operada pelos moradores de Bacurau, percebidas como não equivalentes, os posicionamentos favoráveis se preocupam, também, em apontar as diferenças que separam ações antagônicas. Mais aterradoras do que as facadas de Lunga contra os caçadores americanos são as estruturas sócio-históricas que exploram e oprimem os sujeitos subalternizados que vivem em Bacurau, algo que o filme não deixa de evidenciar. A naturalização de desigualdades e de processos de desumanização - que afetam o vilarejo pernambucano e que sustentam à ação facínora dos estrangeiros - é mais violenta do que qualquer golpe desferido pelo neo-cangaceiro. Afinal, recordamos com Zizek, a violência do tipo "subjetiva" é tão somente a parte mais visível de uma dinâmica que comporta, também, uma violência sistêmica e uma violência simbólica, "encarnada na linguagem e em suas formas". (ZIZEK, 2014, p.16); ambas invisíveis, porque socialmente assimiladas. Os articulistas partidários ao filme denunciam essa "carnificina moral que já vem instalada no HD das almas" (BLOCH, 2019), normalizada e legitimada, como a maior violência encenada na obra. $\mathrm{O}$ grupo de invasores articula violências subjetivas, sistêmicas e simbólicas para lastrear suas ações de extermínio, enquanto o povo de Bacurau se utiliza de 
uma violência subjetiva meramente reativa, com o objetivo maior não de fazer morrer, mas de tentar viver.

As críticas negativas, por sua vez, encaram Bacurau como "um elogio à barbárie", conforme o texto de Eduardo Escorel, para a revista Piauí. A violência cometida pelos populares é percebida como uma vingança desmedida, cruel, que revela a selvageria que paira no remoto povoado. Ela não é contextualizada em uma dinâmica neocolonialista, que perpetua ideologias exploratórias (SHOHAT; STAM, 2006), mas é vista como dado ahistórico. Desvinculada das condições estruturais que explicam suas diferentes manifestações - realidades estas construídas na narrativa cinematográfica - a violência presente em Bacurau é planificada, simplificada. As armas vintage, made in USA, que assassinam famílias sertanejas, carregariam o mesmo peso do bacamarte do velho Damiano que marca, com um disparo certeiro na cabeça do inimigo, o início da revolta.

A tentativa de igualar ou equiparar qualquer representação da violência contida na obra leva críticos como Jerônimo Teixeira, da Folha, a afirmar que "depois da segunda ou terceira decapitação comandada pelo feroz Lunga (Silveiro Pereira), misto de cangaceiro e líder de facção muito admirado em Bacurau, a distinção entre vingança e resistência começa a parecer um tanto abstrata" (TEIXEIRA, 2019). Sugere-se que a resistência não pode ser tão brutal quanto a ameaça que a faz surgir. Desconhecem que "a violência em estado primitivo [...] não pode submeter-se senão perante uma violência maior" (FANON, 1961, p.57). Nessa visada, sujeitos subalternizados não poderiam reivindicar uma estratégia de luta tão eficiente quanto a de seus invasores. Inclusive, Lunga, figura ambígua em várias dimensões, é tratada por certos críticos como bandido. Por ser a personagem que simboliza a violência revolucionária, anti-sistêmica e que ameaça perspectivas políticas conservadoras, tem seu heroísmo dúbio apagado pelos articulistas a cada cabeça cortada. Lunga representa o imaginário da revolução que se pretende, sempre, obscurecer.

Isabela Boscov, colunista da revista Veja, acusa o filme, até mesmo, de xenofobia mesmo que os estrangeiros, em Bacurau, busquem liquidar os nativos. Durval Muniz, que escreve para o blog Saiba Mais, concorda com Boscov. Ele afirma que a retratação dos de fora como a representação do mal soa como gesto "extremamente reacionário, principalmente "numa época de criminalização e ódio aos imigrantes" (MUNIZ, 2019). Os caçadores de pessoas se tornam, para esses autores, vítimas de um nacionalismo intrinsecamente excludente. O filme é depreciado por, supostamente, expressar um preconceito reverso contra os estrangeiros, aniquilados pela comunidade local num banho de sangue. 
A escolha de Réquiem para Matraga, música composta por Geraldo Vandré, como parte da trilha sonora da obra também despertou comentários negativos neste sentido. Eduardo Escorel questiona:

Como devemos entender esses versos entoados de modo a parecer palavras de ordem? Seriam uma forma de Mendonça Filho e Dornelles justificarem seus personagens por fazer justiça com as próprias mãos? Além de desafiar qualquer tentativa de emudecer quem canta (ou filma), a canção e o filme pretendem defender o ato de matar desde "que seja para melhorar?" (ESCOREL, 2019).

Referem-se a Bacurau, o filme, como um discurso panfletário e perigoso, favorável à morte e ao aniquilamento da diferença, e a Bacurau, a cidade, como um lugar que "não hesita em passar sentenças de tortura - lançar um homem seminu no meio dos espinheiros da caatinga, por exemplo" (TEIXEIRA, 2019). Ainda, as referências significativas à história do cangaço sugerem, para Jerônimo Teixeira, que "o vilarejo não foi subitamente convertido à violência pelo invasor americano. Ele só teria reencontrado uma vocação atávica enterrada na alma do lugar, como as armas ocultadas sob a rua de terra" (TEIXEIRA, 2019). A violência orquestrada por Lunga e os demais moradores da região não é percebida, logo, como um recurso de sobrevivência que se perpetuou, historicamente, ao longo das lutas das comunidades desvalidas, mas como uma característica inerente e imanente àquela cultura. A imposição imperialista e a exploração classista que marcam nosso tempo, e que ressoam na diegese configurada por Bacurau, não são tão abjetas a ponto de justificar o antagonismo aguerrido do coletivo que precisa afirmar sua condição de gente.

A receptividade do longa entre o público - especialmente entre grupos identificados com o campo progressista - também provocou descontentamentos em um nicho da crítica jornalística. Durval Muniz sugere que "um regime anacrônico das imagens ligadas ao imaginário da revolução" provoca "a imediata identificação das plateias de esquerda com o filme" e faz com que "muitos saiam do cinema entusiasmados diante de tamanha carnificina" (MUNIZ, 2019). Esse imaginário, para o articulista, reforça "o fascismo e sua apologia da morte e da violência dominam o país" (MUNIZ, 2019). Traça-se um paralelo entre o ímpeto revolucionário e o imaginário fascista, polos supostamente equivalentes de uma mesma linha ideológica. Isabela Boscov afirma que "a lógica de Bacurau, no fundo, é idêntica à do outro extremo, e tão desalentadora quanto ela: para que um lado se construa, é preciso destruir o outro lado - com ira e violência" (BOSCOV, 2019). Rodrigo Perez de Oliveira, do Jornalistas Livres (um veículo, inclusive, identificado com o campo progressista), diz que, a 
partir de Bacurau, compreendemos que "temos a violência como gramática comum e todos nós, bem lá no fundo, somos um pouquinho Bolsonaro" (OLIVEIRA, 2019.).

Essa oposição a qualquer forma de explosão violenta, manifesta nas críticas de veículos tanto à direta como à esquerda do espectro político, é, conforme Zizek, característica de uma atitude liberal do nosso tempo marcada pela cordialidade. Parte-se da premissa arendtiana de que a construção política começa pelo pacto de não usar a força, proposição que desvia as atenções do verdadeiro lugar do problema, que está na interação complexa da violência subjetiva, sistêmica e simbólica. A defesa da não-violência, conforme Franz Fanon (1961), é, de fato, apenas uma estratégia de ajuste do colonialismo para evitar "qualquer gesto irrecuperável, qualquer efusão de sangue, qualquer ato lamentável” (FANON, 1961, p.) que ameace a ordem vigente. E é importante lembrar que até mesmo Hannah Arendt reconhece que "em certas circunstâncias, a violência - o agir sem argumentar, sem o discurso ou sem contar com as consequências - é o único modo de reequilibrar as balanças da justiça" (ARENDT, 2014, p. 82). Contra as críticas negativas à resistência, Rodrigo Nunes pondera, em texto para o El País, que

...a violência que o filme vinga, passada, presente e futura, é aquela que existe nas fronteiras do capitalismo e do Estado. É a violência a que estão expostos aqueles que, sem nunca serem incluídos por completo nem nos serviços públicos nem no mercado, podem a qualquer momento se tornar objetos do poder político ou do interesse econômico. (NUNES, 2019).

Reacende-se feridas abertas no trauma mal curado da escravidão e dos modelos autoritários que sempre estiveram presentes nas relações entre classes. A quem os direitos nunca foram reclamados, acusa-se, na alegoria da realidade, de promover a brutalidade. No caso do Brasil é melhor não se aproximar de qualquer inferência a revolução, pois, mesmo nomeando-a de "anacrônica", trata-se de um imaginário que os discursos dominantes, reverberados por parte da crítica especializada, não pretendem estimular.

\section{A CRÍTICA DA CRÍTICA: A POLÊMICA EM CARNE E OSSO}

Para além dos aspectos internos ao filme - da forma ao conteúdo - os artigos jornalísticos abordaram o próprio embate polêmico estabelecido entre eles. A partir de um exercício metacrítico - de crítica das críticas (PAGANOTTI; SOARES, 2019) - estes textos confrontaram suas múltiplas aproximações com a obra investigada. Assim como nas 
polarizações políticas observadas no Brasil nos últimos anos, procurou-se anular o efeito do argumento contrário, nem sempre se estimulando o debate.

No campo das recepções negativas, alguns críticos buscaram recuperar considerações adversas sobre Bacurau propostas por outros autores. Trabalhou-se com aspectos do filme que foram rejeitados pela crítica internacional, selecionados cuidadosamente em uma contranarrativa que turva as evidências de reconhecimento da obra, adquiridas principalmente com a premiação no Festival Cannes. Em seu artigo para a revista Piauí, Eduardo Escorel afirma que rejeições estrangeiras foram ignoradas, por exemplo, nos anúncios promocionais do filme:

As frases de venda ocultam, além do mais, nuances das críticas de onde foram extraídas. Em meio aos elogios, uma define Bacurau como um "perturbador surto ultraviolento no interior do Brasil", assinalando que "é um filme realmente estranho" que se torna "um banho de sangue no estilo jacobino". (ESCOREL, 2019).

Busca-se evidenciar que a recepção internacional confirma as percepções do segmento da crítica brasileira que não se entusiasmou com a obra, principalmente devido à violência nela contida. Por outro lado, quando confrontados por recepções do exterior favoráveis ao filme, os articulistas indispostos com o trabalho de Mendonça Filho e Dornelles optam, em alguns casos, por deslegitimá-las. Acusa-se esta crítica, por exemplo, de podar a autonomia do público brasileiro, supostamente constrangido de formular percepções autônomas sobre Bacurau, como argumenta Andrea Ormond, da revista Cinética:

Tenho com a ideia de "sucesso internacional" para o cinema feito no Brasil certa relação melancólica, quase entediada. Muita gente vem chamando atenção sobre isso, e também me causa receio que os filmes do Kleber cheguem sempre ao público com o vaticínio de "aprovados no exterior". (ORMOND, 2019).

Quando a metacrítica é efetuada dentro do circuito nacional, a batalha discursiva ganha novos contornos. O confronto sobre cinema se mistura com a polarização política do Brasil contemporâneo, como se percebe na discussão direta entre Demétrio Magnoli e Inácio de Araújo, ambos colunistas da Folha de S. Paulo. Araújo, identificado com o campo progressista, defende a união da população diante da ameaça de fora, ao que Magnoli, representante de um pensamento à direita desse espectro, responde: “a 'ameaça de morte' é só o espantalho erguido por 'intelectuais orgânicos' para evitar o exame crítico do fracasso lulopetista entre indivíduos de esquerda" (MAGNOLI, 2019). Para ele, Bacurau é uma peça 
de propaganda política, e não uma produção artística. Araújo, por sua vez, não nega a vocação propagandística de Bacurau e defende sua vinculação com o campo da arte. Pondera, por exemplo, que “'O Nascimento de uma Nação’ foi uma grande propaganda da Ku Klux Klan, nem por isso é um filme menor. Ao contrário. Se quisermos ir à esquerda, digamos que o 'Encouraçado Potenkim' é igualmente uma obra de propaganda. Nem por isso é menor” (ARAUJO, 2019). Celebra, portanto, o potencial convocatório de um filme que conclama a valorização do povo. No entanto, para Magnoli, o cinema, nessa visada, "deixa de ter interesse público, segregando-se na bolha dos fiéis do Partido" (MAGNOLI, 2019).

As opiniões contraditórias são ordenadas em uma evidente dicotomização na qual se excluem mutuamente. A incapacidade de reconciliação caracteriza a polêmica estabelecida entre esses e outros articulistas, empenhados em desacreditar o discurso sustentado pelo opositor. Ao retomarmos Amossy, que afirma que a desqualificação de um pensamento sempre vem acompanhada do rebaixamento do grupo que ele representa, podemos aferir que as críticas de Bacurau são radicalizadas por causa de sua vinculação com questões previamente polarizadas na sociedade brasileira. O consenso é tão improvável que Magnoli recusa, até mesmo, a celebração de Araújo diante do fato de "um autor que, habitualmente, não trata do cinema' (isto é, eu) abordar o tema. Seria um mérito de Bacurau. Errado, novamente: não tratei de cinema, mas de cultura política. 'Bacurau' não tem méritos (exceto Gal e "Não Identificado')" (MAGNOLI, 2019). Para se aniquilar o imaginário opositor, é necessário destruí-lo até na ficção.

\section{BREVES CONSIDERAÇÕES}

Ao propor uma distopia neoliberal do Estado mínimo, Bacurau se afirma em meio à crítica especializada como uma vigorosa polêmica, que sustenta mais um pretexto para o embate político brasileiro. Na obra, o encontro das reflexões teóricas sobre o país se materializa em forma de um debate que atualiza dissonâncias sobre os caminhos de uma nação. As críticas negativas se referem principalmente ao recurso da violência explorado no filme, aos argumentos políticos fundados na questionável equivalência entre direita e esquerda e as falhas na manipulação dos elementos estéticos e formais da obra. As críticas favoráveis se fundam num contexto que reivindica outras temporalidades inspiradoras da vida no presente. Para isso, reconhecem e acionam simbologias e alegorias de diferentes épocas que podem ser identificadas em fluxos diversos que aparecem na tela. Diante da persistente 
violência, das opressões, dos reiterados fantasmas que voltam a assombrar o Brasil, impelindo-o a uma neoescravidão, qual tradição se reivindica?

De um horizonte possível de respostas a polêmica é talvez o único recurso que não podemos dispensar nesse enfrentamento. Afirmar sua positividade é entender sua importante função na democracia. A polêmica abre a possibilidade de problematizar conflitos que seriam insolúveis sem uma discussão pública. Neste sentido, a disputa de significação em torno de Bacurau demonstra o quanto a polêmica pode ser salutar, abrindo caminhos e condições para a emergência conflitante de culturas e representações, instituindo referências plurais de modos de ver o mundo.

\section{REFERÊNCIAS}

AMOSSY, Ruth. Apologia da polêmica. São Paulo: Contexto, 2017.

ARAÚJO, Inácio. Réplica: Críticos dizem que 'Bacurau’ é um filme de propaganda; e daí? Folha de São Paulo, São Paulo, 16 set.2019. Opinião/Cinema Disponível em <https://www1.folha.uol.com.br/ilustrada/2019/09/criticos-dizem-que-bacurau-e-um-filme-depropaganda-e-dai.shtml>. Acesso em 10 de out de 2019.

ARENDT, Hannah. Sobre a violência. Rio de Janeiro: Civilização Brasileira, 2014.

BENTES, Ivana. Bacurau e a síntese do Brasil brutal. Cult, São Paulo, 29 ago. 2019. <https://revistacult.uol.com.br/home/bacurau-kleber-mendonca-filho/>. Acesso em 10 out de 2019.

BLOCH, Arnaldo. Em 'Bacurau', Kleber vira um Tarantino do faroeste pernambucano. O Globo, Rio de Janeiro, 12 ago. 2019. Disponível em: < https://oglobo.globo.com/cultura/em-bacurau-kleber-viraum-tarantino-do-faroeste-pernambucano-23872799>. Acesso em: 8 out 2019.

BOSCOV, Isabela. Lógica de 'Bacurau' é tão desalentadora quanto a do extremo oposto. Veja, São Paulo, 30 ago. 2019. Entretenimento. Disponível em <https://veja.abril.com.br/blog/isabelaboscov/bacurau/>. Acesso em 10 ou de 2019.

BURKE, Peter. O que é história cultural? Rio de Janeiro: Zahar, 2008.

COELHO, Marcelo. 'Bacurau', ou bolsonarismo às avessas. Folha de S. Paulo, São Paulo, 4 set. 2019. Opinião. Disponível em <https://www1.folha.uol.com.br/colunas/marcelocoelho/2019/09/bacurau-ou-bolsonarismo-asavessas.shtml >. Acesso em 10 out 2019.

COUTO, José Geraldo. A hora e a vez de Bacurau. Blog de cinema, Rio de Janeiro, 29 ago. 2019. Disponível em <https://ims.com.br/blog-do-cinema/bacurau-por-jose-geraldo-couto/>. Acesso em 10 out de 2019.

ESCOREL, Eduardo. Bacurau: celebração da barbárie. Piauí/ Folha de S. Paulo, São Paulo, 28 ago. 2019. Disponível em < https://piaui.folha.uol.com.br/bacurau-celebracao-da-barbarie/> Acesso em 08 de out de 2019.

FANON, Franz. Os condenados da terra. Lisboa: Ulisseia Limitada, 1961. 
FOUCAULT, M. A ordem do discurso: aula inaugural no Collége de France, Pronunciada em 2 de dezembro de 1970. São Paulo: Loyola, 1999.

FORLIN, Miguel. A baixeza de Bacurau. Estado de São Paulo, São Paulo, 28 ago. 2019. Disponível em: <https://estadodaarte.estadao.com.br/a-baixeza-de-bacurau/>. Acesso em 8 out 2019.

HALL, S. Cultura e Representação. Rio de Janeiro: Ed. PUC-Rio/Apicuri, 2016.

MAGNOLI, Demétrio. Tréplica: Em 'Bacurau', cinema deixa interesse público, segregando-se na bolha do Partido. Folha de S. Paulo, São Paulo, 17 set. 2019. Opinião/Cinema. Disponível em < https://www1.folha.uol.com.br/ilustrada/2019/09/em-bacurau-o-cinema-deixa-de-ter-interessepublico-segregando-se-na-bolha-do-partido.shtml?loggedpaywall>. Acesso em 10 out de 2019.

MUNIZ, Durval. Bacurau: será mesmo resistência? Saiba Mais Agência de Reportagem, 15 set. 2019. Opinião. Disponível em: < https://www.saibamais.jor.br/bacurau-sera-mesmo-resistencia/>. Acesso em 7 out 2019.

NUNES, Rodrigo. 'Bacurau' não é sobre o presente, mas o futuro, In: El país, São Paulo, 6 out. 2019. Cultura. Disponível em:

<https://brasil.elpais.com/brasil/2019/10/05/cultura/1570306373_739263.html> Acesso em 10 de out de 2019.

OLIVEIRA, Rodrigo Perez. Baucau nos deu uma má notícia. Jornalistas Livres, 24 set. 2019. Artigo. Disponível em: < https://jornalistaslivres.org/tag/bacurau/>. Acesso em 7 out 2019.

ORMOND, Andrea. Brasileiros são os outros. Cinética: cinema e crítica, 12 set. 2019. Cinema e Crítica. Disponível em <http://revistacinetica.com.br/nova/bacurau-andrea/> Acesso em 10 de out de 2019.

PESSÔA, Samuel. Em Bacurau, o inferno são os outros. Folha de S. Paulo, São Paulo, 15 set. 2019. Colunas e blogs. Disponível em: < https://www1.folha.uol.com.br/colunas/samuelpessoa/2019/09/embacurau-o-inferno-sao-os-outros.shtml>. Acesso em 8 out 2019.

SHOHAT, Ella; STAM, Robert. Crítica da imagem eurocêntrica. São Paulo: CosacNaify, 2006.

SILVA, G.; SOARES, R. Lugares da crítica na cultura midiática. Comunicação, mídia e consumo. São Paulo, v.13. n.37, 2016.

SOARES, R.; PAGANOTTI, I. A meta para a crítica da/na mídia em abordagens metacríticas. Matrizes, v.13, n.2, São Paulo, 2019.

TEIXEIRA, Jerônimo. É contraditório que 'Bacurau' se contraponha a Bolsonaro com violência. Folha de São Paulo, São Paulo, 24 ago. 2019. Opinião. Disponível em <https://www1.folha.uol.com.br/ilustrada/2019/08/e-contraditorio-que-bacurau-se-contraponha-abolsonaro-com-violencia.shtml>. Acesso em 10 out 2019.

WILLIAMS, Raymond. Cultura. Rio de Janeiro: Paz e Terra, 1992.

XAVIER, Ismail. O discurso cinematográfico: a opacidade e a transparência. São Paulo: Paz e Terra, 2005.

ZANIN, Luiz. A força de 'Bacurau é simbolizar nossa falha trágica. Estado de São Paulo, São Paulo, 12 set. 2019. Cultura Disponível em: < https://cultura.estadao.com.br/blogs/luiz-zanin/a-forca-debacurau-e-simbolizar-nossa-falha-tragica/>. Acesso em 6 out 2019.

ZIZEK, Slavoj. Da violência. São Paulo: Boitempo, 2014. 
Professor do Programa de Pós-Graduação em Comunicação Social e dos cursos de Jornalismo e Cinema e Audiovisual da PUC Minas. Doutor em Letras: Linguística e Língua Portuguesa pela PUC Minas e mestre em Comunicação Social pela UFMG. É coordenador do Centro de Crítica da Mídia da PUC Minas e vice coordenador do grupo de pesquisa Mídia e Narrativa.

\section{Juliana Gusman}

Doutoranda em Cultura Audiovisual e Comunicação pelo Programa de Pós-Graduação em Meios e Processos Audiovisuais da ECA-USP. Mestre em Comunicação Social e Bacharel em Jornalismo pela PUC Minas. É membro dos grupos de pesquisa MidiAto (ECA-SUP) e Mídia e Narrativa (PUC

Minas).

\section{@®९@}

Esta obra está licenciada com uma Licença

Creative Commons Atribuição-NãoComercial-CompartilhaIgual 4.0 Internacional 